\title{
Os impactos das atividades extensionistas na formação dos professores universitários
}

Carla de Almeida Soares

Mestre em Educação pela Pontifícia Universidade Católica de Minas Gerais (PUC Minas). Professora do curso de Pedagogia do Centro Universitário UNA.

carlasoaresprof@yahoo.com.br

Iracema Campos Cusati

Mestre em Educação pela Universidade Federal de São Carlos (UFSCar). Professora dos cursos de Pedagogia do Centro Universitário UNA e da Faculdade de Educação da Universidade do Estado de Minas Gerais (FaE/UEMG).

iracema.bh@terra.com.br

\section{Resumo}

Este trabalho é uma pesquisa em desenvolvimento cuja problemática é orientada por questões norteadoras: Quais são os impactos das atividades extensionistas na formação dos professores universitários? Como a atuação e o envolvimento nas atividades extensionistas, proporcionada pelas Instituições de Ensino Superior (IES), interferem na formação continuada desses profissionais? Numa investigação que busca articular a construção e a reconstrução do "fazerdocente" com a reflexão sobre a própria prática pedagógica, pretendemos identificar e compreender as trajetórias de formação e de transformação desses docentes. Nossa discussão orienta-se pelos estudos de Tardif sobre saberes docentes e de Schön e Zeichner que enfatizam os saberes profissionais dos docentes. Deparamos com a necessidade de buscar alternativas que viabilizem mudanças na prática profissional do professor com uma nova visão de compreender, de praticar e de organizar o trabalho docente. Nesse cenário, a epistemologia da prática profissional vem sendo constituída com um novo enfoque, apontando para a melhoria na formação do professor, buscando atender aos desafios da contemporaneidade. Há estudiosos mostrando uma tendência a não separação entre formação e profissionalização, salientando a 
situação atual da docência e indicando novos caminhos que não separam a formação inicial da formação continuada, tendo a prática docente como referência e elemento integrante do seu processo de formação. Nesse sentido, a reflexão sobre como a formação proporcionada pelas atividades extensionistas interferem no desempenho do professor universitário poderá auxiliar na descrição dos conhecimentos necessários ao exercício docente em atividades de pesquisa e extensão, analisando o papel das instituições públicas e privadas na formação continuada de seus profissionais. Os dados a serem analisados são provenientes de entrevistas semiestruturadas desenvolvidas com os professores e alunos participantes do Projeto Escola Integrada e serão submetidos a uma análise do discurso, pois nos interessa o sentido dos enunciados para captar, nos depoimentos, as relações, os limites e as possibilidades da interface formação e atuação docentes.

Palavras-chave: atividades extensionistas; formação docente; saberes docentes.

\section{Introdução}

Com o objetivo de ampliar o espaço/tempo de aprendizagem dos alunos das escolas municipais, fazendo da cidade uma grande sala de aula, o programa Escola Integrada, desenvolvido pela prefeitura de Belo Horizonte, tem grande impacto socioeducativo. Toda a sociedade é convocada a contribuir com a melhoria da educação na cidade. Nesse sentido, as universidades têm um papel importante no processo. Por meio da oferta de oficinas dos mais diversos temas, os universitários terão a oportunidade de trabalhar e construir conhecimentos com crianças e adolescentes das escolas municipais, em um movimento contínuo de trocas e aprendizagens mútuas. Por vez, os professores universitários também estão imersos em um processo de formação, diante das orientações e do acompanhamento periódico da atuação dos alunosestagiários e de todo o trabalho desenvolvido nas escolas, buscando cada vez mais a qualidade e comprometimento com o projeto proposto.

Esse programa é uma proposta pedagógica destinada ao desenvolvimento de ações educativas complementares. Seu principal objetivo é dar oportunidade às crianças e adolescentes matriculados em escolas da rede municipal de educação para que desenvolvam o seu potencial por meio de uma formação integral com o aprimoramento de competências individuais, sociais, produti- 
vas e cognitivas. Assim, o programa em questão visa promover a cidadania por meio de ações que favoreçam a ampliação e a melhoria da aprendizagem dos alunos nos aspectos afetivo, moral, intelectual e social, primando pela inserção desses sujeitos nos diversos espaços da sociedade. Além disso, propicia a participação da população nas atividades, envolvendo alunos, monitores, professores, coordenadores, IES e o município.

Segundo informações apresentadas pela prefeitura de Belo Horizonte (2006)', o programa Escola Integrada está implantado em cinquenta escolas da rede e atende 15 mil crianças e adolescentes do ensino fundamental, de seis a 14 anos. Os estudantes são atendidos em horário integral, ou seja, manhã e tarde, incluindo horário de almoço, e as atividades são realizadas dentro e fora da escola, em diversos lugares da comunidade.

As ações propostas pelo programa têm a intenção de ser multi, trans e interdisciplinares, por meio da integração de diferentes programas públicos e sociais. A base é a interssetorialidade e o compartilhamento de ações entre as Secretarias Municipais de Educação, Políticas Sociais, Esportes, Regulação Urbana, Saúde e a Fundação Municipal de Cultura, sob a coordenação da Secretaria Municipal de Planejamento, Orçamento e Informação. São privilegiadas tanto as competências voltadas para os aspectos intelectuais, quanto às competências voltadas para a música, artes e esportes em geral.

A pesquisa que propomos visa conhecer quais são os impactos das atividades extensionistas na formação dos professores do ensino superior. Nosso interesse é compreender qual a interferência da atuação e do envolvimento da Instituição de Ensino Superior na atividade extensionista do programa Escola Integrada para a formação continuada desses profissionais. Numa investigação que busca articular a construção e a reconstrução do "fazer-docente" com a reflexão sobre a própria prática pedagógica, pretendemos identificar e compreender as trajetórias de formação e de transformação desses docentes universitários.

\section{Relação entre formação de professor e trabalho docente}

Os estudos produzidos sobre a formação e o trabalho do professor têm apresentado mudanças ao longo das décadas. As linhas de pesquisa, até a década de 1960, centravam suas investigações em encontrar características pessoais do professor e em relacioná-las à aprendizagem dos alunos.

' Disponível em www.pbh.gov.br. 
No início da década de 1970, as investigações sobre o professor sofreram uma mudança de paradigma ao focalizarem os estudos não mais em características pessoais, mas na situação de ensino propriamente dita, centrando-se na observação e análise de atuação docente. No final dessa década, a ênfase na investigação sobre o professor se volta para os processos de pensamento e de tomada de decisões dos professores durante sua atividade profissional.

Embora não seja um tema novo, a discussão sobre a formação do educador vem se destacando muito nas conferências e seminários sobre educação desde o final da década de 1970. Naquela época, iniciou-se um movimento de reflexão sobre a escola brasileira, partindo de sua realidade e buscando caminhos que permitissem que a escola e o ensino saíssem da crise em que se encontravam. A preocupação com o fracasso escolar levou os educadores à discussão e à análise dos fatores responsáveis pela baixa qualidade do ensino e despertou-os para a possibilidade de se oferecer uma boa escola à população de baixa renda. Evidencia-se a necessidade de melhorar a formação dos professores como condição para a melhoria da qualidade do ensino em geral.

Os enfoques investigativos do início da década 1980 referem-se ao caráter político da prática pedagógica e ao compromisso do educador com as 52 classes populares. Naquele momento, procurou-se definir a natureza da função docente e o papel do professor para se direcionar as reformas dos cursos de formação de professores. Após os primeiros anos daquela década, a preocupação com a formação técnica do professor ganhou considerável importância, sem desconsiderar a questão da formação política do futuro docente (MELLO, 1987). Nesse contexto, a competência técnica² à qual subjaz um suporte pedagógico e um compromisso educacional e social, apresentase como condição necessária para que o educador assuma um compromisso político. Enfatizava-se a necessidade de uma formação técnica que envolvesse o conhecimento pedagógico e o específico de determinado campo. Durante a década de 1980, vários educadores se manifestam, criticando a estrutura e o conteúdo dos cursos de formação de professores e especialistas. Nos estudos dos processos de pensamento e ação do professor destacamse duas dimensões da cognição: o processamento de informações e a tomada de decisões. O paradigma norteado pelo pensamento do professor deu início a diversas investigações que analisaram os tipos de conhecimentos que

\footnotetext{
${ }^{2}$ A competência técnica, o saber fazer bem. Para isso, é necessário o "domínio do conteúdo do saber escolar e dos métodos adequados para se transmitir este conteúdo do saber escolar às crianças que não apresentam pré-condições idealmente estabelecidas para sua aprendizagem" (MELLO, 1987, p. 15).
} 
os professores elaboram e utilizam no cotidiano escolar.

Na década de 1990, surge a valorização dos saberes da experiência a partir das discussões sobre os saberes que um professor precisa ter para tornar-se um profissional da educação. Na segunda metade dessa década, a discussão centra-se na questão do desenvolvimento profissional do professor. Emerge a necessidade de uma formação que garanta ao futuro profissional ser agente da construção e da gerência de seus conhecimentos. A noção de desenvolvimento profissional sobre a qual debruçamos, embora esteja próxima à noção de formação, não é equivalente, pois, ao contrário da formação em que o professor é objeto, nessa nova concepção o professor é sujeito do seu desenvolvimento profissional. Trabalhar na perspectiva do desenvolvimento profissional é identificar no docente suas potencialidades de autônomo e responsável pela construção de saberes. Percebe-se, portanto, a importância dos estudos realizados no âmbito do paradigma do pensamento do professor no que concerne às contribuições para reconceituá-lo enquanto profissional e intervir nos cursos de formação.

\section{Investigando formação e atuação docentes}

A decisão de investigar os impactos das atividades extensionistas na formação dos professores universitários, com base no trabalho docente, iniciou em nossas preocupações como professoras-orientadoras do programa Escola Integrada nas instituições em que atuamos. Dois importantes motivos justificam a escolha desse programa: o primeiro, de ordem prática, é a parceria da instituição de ensino superior com o programa em questão e seu compromisso em integrar teoria e prática, articulando ensino-aprendizagem com necessidades e demandas sociais, promovendo, enfim, a criatividade, a iniciativa e a consciência cidadã. O segundo motivo, de ordem da política pública, diz respeito ao fato de que, conforme define a Lei de Diretrizes e Bases da Educação Nacional (LDBEN) de 1996, em seu artigo 43, inciso VI, cabe à educação superior "estimular o conhecimento dos problemas do mundo presente, em particular os nacionais e regionais, prestar serviços especializados à comunidade $\mathrm{e}$ estabelecer com esta uma relação de reciprocidade" (BRASIL, 1996).

Acreditamos que esta pesquisa poderá levar a um melhor entendimento das novas perspectivas para a formação e atuação de professores, contribuindo para o aprofundamento e a superação de questões relacionadas à forma- 
ção e à prática pedagógica dos docentes universitários.

O objetivo geral da pesquisa é conhecer e analisar os impactos das atividades extensionistas na formação dos professores universitários que orientam alunos-estagiários do programa Escola Integrada da prefeitura de Belo Horizonte. Além desse, os objetivos específicos são:

- Analisar em que medida a formação desses profissionais está vinculada com os interesses e as necessidades do programa Escola Integrada;

- Verificar quais são as situações e as atividades de trabalho que resgatam o fazer pedagógico nas orientações dos alunos-estagiários;

- Refletir sobre como a formação proporcionada pelas atividades extensionistas interferiram, se contribuem ou não para o desempenho desses professores universitários;

- Detectar a relação existente entre a formação desses professores e as experiências narradas pelos alunos-estagiários no processo de suas orientações;

- Descrever os conhecimentos necessários ao exercício da atuação de professor-orientador do programa Escola Integrada, analisando o papel da instituição de ensino superior na formação continuada desse profissional;

Algumas perguntas nortearam nossa investigação. São elas:

54 - Como a formação proporcionada pelas atividades extensionistas interferiram, se contribuindo ou não para o desempenho desses professores universitários?

- Que tipos de trabalhos/orientação eles desenvolvem juntamente com seus alunos? - Quais são os principais dispositivos e caminhos viabilizados pela instituição de ensino superior e prefeitura de Belo Horizonte que servem para engendrar a prática pedagógica desses profissionais?

- De que modo a formação inicial e/ou continuada interferiu, contribuiu ou não para o desempenho desses professores universitários nas orientações viabilizadas pelos alunos-estagiários?

- Quais são os conhecimentos necessários ao exercício da atuação de professor-orientador no programa Escola Integrada?

Como referenciais teóricos, destacamos Tardif, enfatizando os saberes profissionais dos docentes, bem como Schön e Zeichner que abordam o significado da preparação de docentes para o exercício de uma prática reflexiva. Segundo Tardif, "a prática profissional é o conjunto dos saberes utilizados realmente pelos profissionais em seu espaço de trabalho cotidiano para desempenhar todas as suas tarefas" (TARDIF, 2002, p. I3). Esses saberes englobam os conhecimentos, competências, habilidades e atitudes do professor, isto é, "sa- 
ber-fazer". Tardif considera que o objetivo da "epistemologia da prática profissional é revelar esses saberes, compreender como são integrados concretamente nas tarefas dos profissionais e como estes os incorporam, produzem, utilizam, aplicam, e transformam em função dos limites e dos recursos inerentes às suas atividades de trabalho" (TARDIF, 2002, p.I I).

Atualmente ao pesquisar sobre a formação de professores e a prática docente, encontramos em relevância a necessidade de repensar e buscar alternativas que viabilizem mudanças na prática profissional do professor com uma nova visão de entender, praticar e organizar o trabalho docente. Nesse cenário, a epistemologia da prática profissional vem sendo constituída com um novo enfoque, apontando para a melhor qualidade na formação do professor no sentido de atender aos desafios da contemporaneidade.

Nesse contexto, há várias correntes de estudo mostrando uma forte tendência a não separação entre formação e profissionalização, salientando a situação atual da docência, bem como indicando novos caminhos que não separam a formação inicial da formação continuada, tendo a prática docente como referência e elemento integrante do seu processo de formação. Essa prática não está relacionada só com a formação técnica do professor, mas também com a experiência do "saber-fazer" característico da docência, bem como dos conhecimentos específicos que estão inerentes a essa prática.

Os professores, enquanto sujeitos sócio-histórico-culturais, possuem certos saberes que são produzidos e utilizados por eles em seus trabalhos educativos diários. A prática dos professores não é somente a aplicação da teoria e de conhecimentos universitários, mas é também produção de saberes originados nessa mesma prática. Tardif (2002) refere-se ao professor de profissão como aquele que atua em sala de aula, que possui conhecimento, desenvolve e aplica teorias, saberes de sua própria ação, de sua prática. Segundo ele, "os professores de profissão possuem saberes específicos que são mobilizados, utilizados e produzidos por eles no âmbito de suas tarefas cotidianas" (Tardif, 2002, p.228). Nessa perspectiva, assim se posiciona em relação à prática docente:

os professores são sujeitos do conhecimento e possuem saberes específicos ao seu ofício [...] A prática deles, ou seja, seu trabalho cotidiano, não é somente um lugar de aplicação de saberes produzidos por outros, mas também um espaço de produção, de transformação e de mobilização de saberes que lhe são próprios (TARDIF, 2002, p. 237) 
O sujeito é, portanto, constituído com base nos efeitos das relações interpessoais e, para buscar entendê-lo, há de se considerar o processo de construção da identidade de professores e professoras, percebendo-os como construção múltipla de cada sujeito do ato educativo.

Segundo Soares (2004), no bojo dos questionamentos e das discussões sobre a formação de professores e sobre a epistemologia da prática, destaca-se Donald Schön, que contribui para a divulgação das teorias que abordam essas questões com duas obras. Uma é a "The reflective practitioner" (1983), que propõe uma epistemologia da prática, tendo como referência as competências que se encontram subjacentes à prática dos bons profissionais. A outra, "Educating the reflective practitioner" ( 1987 ), explicita o seu pensamento pedagógico, defendendo que a reflexão deve fazer parte da formação do futuro profissional a partir de situações práticas reais (Alarcão, 1996, p. I6). Segundo Alarcão, Schön considera a reflexão como "a via possível para um profissional se sentir capaz de enfrentar as situações sempre novas e diferentes com que vai deparar na vida real e de tomar as decisões apropriadas nas zonas de indefinição que a caracterizam" (ALARCÃO, 1996, p. 12).

Para Schön, os cursos de formação devem preparar os professores para lidarem com situações novas, ambíguas, confusas, onde muitas vezes as teorias aplicadas, as técnicas de decisão e os raciocínios não fornecem soluções lineares. Essa formação deve proporcionar aos professores uma situação de prática orientada com o objetivo de iniciação à profissão. Essa ideia é nomeada por Schön como "practicum" e cabe ao professor formador propiciar essa situação de prática,

reservando para o profissional orientador a designação de coach, aquele que organiza situações em que $o$ aluno possa praticar e confrontar-se com problemas reais cuja resolução implique reflexão, levantamento e verificação de hipóteses, experiência de ter cometido erros, consciência da necessidade e do valor da ajuda dos outros, assim como do aperfeiçoamento constante, que tem a sua origem no auto-conhecimento operativo (ALARCÃO, I996, p. 20).

Frente a essa oportunidade, os professores aprendem a fazer, fazendo, aproximando os alunos da realidade, embora sem correr riscos, pressões e possíveis contradições que, na prática, poderiam levar a certos danos irreparáveis.

Para Soares (2004), o foco da teoria de Schön está na formação do professor reflexivo, a partir de um novo entendimento da prática docente, onde a experiência ganha relevância enquanto parte do "saber-fazer" próprio da profissão. Ele defende que na formação do futuro profissional deva ter o com- 
ponente da reflexão em situações reais da prática, pois acredita que essa prática está inerente a uma competência do professor. Segundo ele, essa competência remete a um profissionalismo eficiente, criativo e inteligente, um "saber-fazer" que leva o professor a agir em situações novas, indeterminadas, baseando-se em um conhecimento tácito, isto é, "[...] um conhecimento que é inerente e simultâneo às suas ações e completa o conhecimento que lhes vem da ciência e das técnicas que também dominam" (ALARCÃO, 1996, p. I7-18).

Um outro momento do processo de reflexão do professor é aquele da reflexão sobre a reflexão na ação. Nesse momento o profissional busca a compreensão da prática, elabora sua interpretação e tem possibilidade de criar outras formas para a situação em questão. Segundo Campos e Pessoa (200I),

\begin{abstract}
esse momento de reflexão é marcado pela intenção de se refletir sobre a reflexão na ação, de maneira que se consiga produzir uma descrição verbal da reflexão na ação. É necessário ainda a capacidade de se refletir acerca da descrição resultante, podendo-se gerar modificações em ações futuras, ou seja: quando se reflete sobre a reflexão na ação, julgando e compreendendo o problema, podemos imaginar uma solução (CAMPOS; PESSOA, 200I, p.198-199).
\end{abstract}

Outro teórico que se dedicou a estudos da profissão docente na perspectiva do professor reflexivo foi Zeichner, que elaborou seu pensamento valorizando a prática entendida como espaço de produção de conhecimento. Em sua teoria, Zeichner ultrapassa a concepção de Schön, por não pressupor a prática reflexiva de modo individual, mantendo comunicação não apenas com a situação da sala de aula, mas também com outros profissionais. Ele aponta a reflexão como prática social, fazendo uma análise crítica da epistemologia da prática decorrente da perspectiva da reflexão (Soares, 2004). Segundo Campos e Pessoa, Zeichner "considera as condições institucionais e os papéis que cada professor assume na sua prática "(CAMPOS; PESSOA, 1998, p.20I).

Zeichner ressalta vários aspectos do movimento da prática reflexiva no ensino e na formação de professores. Ele ressalta que a prática reflexiva é uma reação dos professores contra o fato de serem considerados técnicos do ensino, cumprindo ordens de terceiros que estão fora da sala de aula, isto é, a não aceitação de uma reforma educacional imposta hierarquicamente e que torna os professores meros receptores passivos. Para ele, essa situação,

[...] implica o reconhecimento de que os professores são profissionais que devem desempenhar um papel ativo na formulação tanto dos propósitos e objetivos do seu trabalho, 
como dos meios para os atingir; isto é, o reconhecimento de que o ensino precisa de voltar às mãos dos professores (ZEICHNER, 1993, p.16).

A partir da constatação de que a produção do conhecimento não ocorre somente nas universidades e nos centros de investigação e desenvolvimento, mas também no interior da sala de aula, onde os professores constroem teorias que contribuem para os conhecimentos do ensino, Zeichner valoriza a experiência que reside na prática dos bons professores.

Segundo Zeichner, além do saber na ação, que o professor acumula ao longo do tempo no seu cotidiano, ele também cria um novo saber. As estratégias de ensino, usadas na sala de aula pelos professores, são baseadas em teorias-práticas sobre o modo de entender os valores educacionais. A prática de todo professor é o resultado de uma ou outra teoria, seja reconhecida ou não. Os professores sempre teorizam diante de problemas pedagógicos. O seguinte comentário de Zeichner ilustra essa questão:

na minha opinião, a teoria pessoal de um professor sobre a razão por que uma lição de leitura correu pior ou melhor do que esperado, é tanto teoria como as teorias geradas nas universidades sobre o ensino da leitura: ambas precisam de ser avaliadas quanto à sua qualidade, mas ambas são teorias sobre a realização de objetivos educacionais. Na minha opinião, a diferença entre teoria e prática é, antes de mais, um desencontro entre a teoria do observador e a do professor, e não um fosso entre a teoria e a prática (ZEICHNER, 1993, p.21).

Esse comentário, além de ilustrar nossa compreensão sobre a prática docente, impulsiona-nos a investigar as atividades desenvolvidas por professores e os impactos em seus percursos formativos. Nessa perspectiva, buscamos compreender como se dá a formação contínua dos professores das IES e os impactos das atividades extensionistas nesse processo formativo.

\section{Considerações finais}

Buscamos conhecer e analisar os impactos das atividades extensionistas na formação dos professores universitários que orientam alunos-estagiários do programa Escola Integrada da prefeitura de Belo Horizonte, bem como descrever os diferentes saberes produzidos pelos sujeitos professores-orientadores nas suas relações educativas desenvolvidas nos espaços em que estão atuando.

Analisamos em que medida a formação desses profissionais está vinculada 
com os interesses e as necessidades do programa Escola Integrada. Para isso, verificamos quais são as situações e as atividades de trabalho que resgatam o fazer pedagógico nas orientações dos alunos-estagiários.

Relativamente à formação de professores, nos últimos anos, houve múltiplas iniciativas institucionais de promover a formação continuada, bem como a discussão sobre a temática. Interrogamos, então, o que essas têm significado em termos de modificação da prática docente e da incorporação e implantação dos resultados de pesquisa nos currículos de formação e no cotidiano escolar. Sabemos que uma proposta de formação continuada a ser desenvolvida deve ser articulada à organicidade do cotidiano escolar, isto é, planejada juntamente com o professor e considerar as condições em que ele atua na escola. Do contrário, pouca influência acarretará na implantação de novas práticas que almejam mudanças. Há inúmeras variáveis intervindo na atuação docente, no âmbito das redes de ensino, tornando complexo o retorno das pesquisas para a sala de aula, conforme destaca Alves-Mazzotti (2003). Também há inúmeras contribuições que os pesquisadores podem propor ao atuarem em processos de formação continuada, na perspectiva de disseminar conhecimentos oriundos das pesquisas sobre formação docente entre professores que lecionam na educação básica.

Para finalizar, sugerimos que devemos planejar um processo dialógico que possibilite identificar e problematizar os obstáculos a serem vencidos por professores para a implantação de práticas pedagógicas que estejam em sintonia com as pesquisas que realizamos. Assim, processos de formação continuada de professores, quando concebidos e efetivados numa perspectiva comunicativa, permitem também articular e elaborar projetos de pesquisa e extensão a partir da identificação dos problemas que emergem da atividade extensionista. É nesse sentido que compreendemos que a nossa produção acadêmica e a intervenção em práticas educacionais constituem pontos importantes para repensar a formação de professores. Esforços deverão ocorrer na busca de alternativas potencializadoras de interações comunicativas, problematizadoras do fazer pedagógico e dialógicas entre pesquisa e extensão.

A reflexão sobre como a formação proporcionada pelas atividades extensionistas interferem contribuindo ou não para o desempenho dos professores universitários pode auxiliar na descrição dos conhecimentos necessários ao exercício da atuação de professor-orientador do programa Escola Integrada. Assim, é possível analisar o papel da instituição de ensino superior na formação continuada desse 
profissional. Numa investigação que busca articular a construção e a reconstrução do "fazer-docente", pretendemos identificar e compreender as trajetórias de formação e de transformação desses docentes universitários.

Enfim, retomamos o papel da comunicação dos resultados da pesquisa na formação continuada de professores, pois numa perspectiva freiriana, a comunicação com seu duplo papel de problematizar e dialogar assumirá sua maior importância. Nem sempre o que os docentes formadores julgam relevante para a formação continuada constitui uma necessidade sentida pelo professor. Contudo, isso não significa que devemos balizar pesquisas em formação continuada simplesmente a partir das demandas de professores, mas sim planejar um processo dialógico que possibilite identificar e problematizar os obstáculos a serem vencidos por professores para a implantação de práticas pedagógicas que estejam em sintonia com as pesquisas que realizamos. Professores têm uma história tanto de formação quanto de atuação profissional que precisam ser consideradas e problematizadas pelos docentes formadores. Assim, processos de formação continuada de professores, quando concebidos e efetivados numa perspectiva comunicativa como a que propõe Freire, permitem também articular e elaborar projetos de pesquisa a partir da identificação pelo

60 pesquisador, bem como da sua formulação, dos problemas que emergem da atividade de extensão. É nesse sentido que a nossa produção acadêmica e a intervenção em práticas educacionais envidam esforços na busca de alternativas potencializadoras de interações comunicativas, problematizadoras e dialógicas entre pesquisa e extensão. 


\section{Referências}

ALARCÃO, I. Reflexão crítica sobre o pensamento de D. Schön e os programas de formação de professores. Revista da Faculdade de Educação. v.22, n. 2, p.I I-42, jul./dez. 1996.

ALVES-MAZZOTTI, A. J. Impacto da pesquisa educacional sobre as práticas escolares. In: ZAGO, N.; CARVALHO, M. P.; VILELA, R. A. T. (org.) Itinerários de pesquisa perspectivas qualitativas em sociologia da educação. Rio de Janeiro: DP\&A Editora, 2003.

BACHELARD, G. O. Racionalismo Aplicado. Rio de Janeiro: Zahar Editores, 1977.

BOGDAN, R. C.; BIKLEN, S. K. Investigação qualitativa em educação: uma introdução à teoria e aos métodos. Tradução de Maria J. Alvarez, et al.In: Coleção ciências da educação, n. 12. Porto: Porto Editora, 1994.

CAMPOS, S. de; PESSOA, V. I. F. Discutindo a formação de professoras e de professores com Donald Schön. In: FIORENTINI, D.; GERALDI, C. M. G.; PEREIRA, E. M. de A. (org.). Cartografias do trabalho docente. Campinas: Mercado das Letras, 1998, p. 183-206.

CONTRERAS, J. A autonomia de professores. São Paulo: Cortez, 2002.

CUSATI, I. C. Aprendendo a ensinar matemática no exercício da profissão: um estudo das fases inicial e final da carreira docente. 183 p. Dissertação (Mestrado em Educação) - Programa de Pós-graduação em Educação da Universidade Federal de São Carlos, 1999.

FREIRE, A. Formação de educadores em serviço: construindo sujeitos, produzindo singularidades. Infância e Educação Infantil. Campinas: Papirus, 1999.

GERALDI, C. M. G.; GUERRA, M. D. S.; MESSIAS, M. da G.M. Refletindo com Zeichner: um encontro orientado por preocupações políticas, 
teóricas e epistemológicas. In: FIORENTINI, D.; GERALDI, C. M. G.; PEREIRA, E. M. de A. (org.). Cartografias do trabalho docente. Campinas: Mercado das Letras, 1998, p.237-274.

GÓMEZ, A. P. O pensamento prático do professor: a formação do professor como profissional reflexivo. In: NÓVOA, A. (org.) Os professores e a sua formação. Lisboa: Nova Enciclopédia, 1997, p.93-II4.

KISHIMOTO, T. M. Política de formação profissional para a educação infantil: pedagogia e normal superior. Educação e sociedade. n. 68, p. 6I-79, dez. 1999.

LOBO, A. P. S. L. A formação do profissional de educação infantil: uma análise no contexto das políticas educacionais na década de 1990 no Brasil. In: PAIVA, E. V. de (org.). Pesquisando a formação de professores. Rio de Janeiro: Dp\&A, 2003, p.169-191.

LUDKE, M.; ANDRÉ, M. E. D. A. Pesquisa em educação: abordagens 62 qualitativas. São Paulo: EPU, 1986.

MELLO, M. G.; N. MELLO, G. N. (1987). Magistério de $I^{\circ}$ grau: da competência técnica ao compromisso político. 7. ed. São Paulo: Cortez: Autores Associados.

NÓVOA, A. Formação de professores e profissão docente. In: NÓVOA, A. (org.) Os professores e a sua formação. Lisboa: Nova Enciclopédia, 1997, p. I5-33.

PAIVA, E. V. de. A formação do professor crítico-reflexivo. In: PAIVA, E. V. de (org.) Pesquisando a formação de professores. Rio de Janeiro: Dp\&A, 2003, p.47-66.

PIMENTA, S. G. Professor reflexivo: construindo uma crítica. In: GHEDIN, E.; PIMENTA, S. G. (org.) Professor reflexivo no Brasil. São Paulo: Cortez, 2002, p. $17-52$. 
RODRIGUES, K. Os números da educação. Presença Pedagógica. Belo Horizonte, v. 9, n. 54, p. 56-63, nov./dez. 2003.

SCHÖN, D. A. Formar professores como profissionais reflexivos. In: NÓVOA, A. (org.). Os professores e a sua formação. Lisboa: Nova Enciclopédia, 1997, p.77-91.

SOARES, C. de A. Curso superior- importante ou necessário? Estudo sobre o nível de formação de professoras da educação infantil. 2004. I23 p. Dissertação (Mestrado em Educação) - Programa de Pós-graduação em Educação da Pontifícia Universidade Católica de Minas Gerais. 2004.

TARDIF, M. Saberes docentes e formação profissional. Petrópolis: Vozes, 2002. . Saberes profissionais dos professores e conhecimentos universitários. Revista Brasileira de Educação. Belo Horizonte, n. I3, p.5-I3, abr. 2000.

ZEICHNER, K. M. A formação reflexiva de professores: idéias e práticas. Lisboa: Educa, 1993.

. Novos caminhos para o practium: uma perspectiva para os anos 90 . In: NÓVOA, A. (org.). Os professores e a sua formação. Lisboa: Nova Enciclopédia, 1997, p. II5-I 38.

. Para além da divisão entre professor-pesquisador acadêmico. In: FIORENTINI, D.; GERALDI, C. M. G.; PEREIRA, E. M. de A. (org.) Cartografias do trabalho docente. Campinas: Mercado das Letras, 1998, p.207-236. 


\section{The impacts of the extension activities in the university teachers' development}

\section{Abstract}

This work is a research in progress oriented by these questions: What are the impacts of the extension activities in the development of university teachers? How do the work and the involvement in the extension activities, supplied by the college/university institutions, interfere in the continued development of these professionals?

We seek to identify and understand the trajectories of the development and transformations of these teachers in an investigation that articulates the construction and reconstruction of the actions of the teachers with the reflection upon the pedagogic practice. Our research is oriented by the studies of Tardif about teacher knowledge and by Schön and Zeichner that emphasize the professional knowledge of the teachers.

We have encountered the need to search for alternatives that lead to changes in the professional practice of the teacher with a new vision of understanding, practicing and organizing the teacher's work. In order to do so, the epistemology of the professional practice has been constituted by a new focus, pointing to the improvement of the teacher's training and seeking to deal with the challenges of contemporaneity.

There are some researchers that show a tendency to the non-separation between the development and the professionalization, focusing in the actual situation of teaching and indicating new routes that do not separate the initial development from the on-going development. These researchers consider the teachers' practice as a reference and fundamental element of their development process. Therefore, the reflection can assist in the description of the necessary knowledge to the work of a teacher in activities of research and extension by analyzing the role of the public and private institutions in the continued development of their professionals.

The data to be analyzed come from semi-structured interviews with teachers and students of the Project Escola Integrada. They will be analyzed according to discourse analysis because we are interested in the relations, limits and possibilities of the development interface and in the teachers' actions.

Keywords: extension activities; teacher's training; teacher knowledge; teacher's work. 